Bull. Chem. Soc. Ethiop. 2012, 26(3), 383-394.

ISSN 1011-3924

Printed in Ethiopia

DOI: http://dx.doi.org/10.4314/bcse.v26i3.7

(C) 2012 Chemical Society of Ethiopia

\title{
CHEMICAL SPECIATION OF L-GLUTAMINE COMPLEXES WITH Co(II), Ni(II) AND Cu(II) IN CATIONIC MICELLAR MEDIUM
}

\author{
Gandham Hima Bindu ${ }^{1}$ and Gollapalli Nageswara Rao ${ }^{2 *}$ \\ ${ }^{1}$ Department of Engineering Chemistry and ${ }^{2}$ Department of Inorganic \& Analytical Chemistry, \\ Andhra University, Visakhapatnam-530 003, India
}

(Received November 10, 2010; revised August 8, 2012)

\begin{abstract}
The impact of cationic micelles on the protonation equilibria of L-glutamine and chemical speciation of its complexes with $\mathrm{Co}$ (II), $\mathrm{Ni}$ (II) and $\mathrm{Cu}$ (II) have been studied by monitoring hydrogen ion concentration $\mathrm{pH}$ metrically at $303 \mathrm{~K}$ and at an ionic strength of $0.16 \mathrm{M}$. The protonation constants and binary stability constants have been calculated with the computer program MINIQUAD75. The best fit chemical models are selected based on standard deviations in the model parameters and residual analysis using crystallographic Rfactor and sum of squares of residuals in all mass-balance equations. The trend in the variation of stability constants of the complexes with mole fraction of the surfactant is attributed to the compartmentalization of complexation equilibria. Distribution of species and effect of influential parameters on chemical speciation have also been presented.
\end{abstract}

KEY WORDS: Chemical speciation, complex equilibria, L-glutamine, cationic micelles

\section{INTRODUCTION}

In humans, glutamine (Gln) is the most abundant amino acid in the extra and intracellular compartments, contributing to greater than $50 \%$ of the free amino acid pool in muscle $[1,2]$. Glutamine is involved in many metabolic and synthetic biochemical processes. It is the preferred energy source for the rapidly proliferating cells of the gastrointestinal tract and the immune system [3- 6]. Regulatory functions of glutamine in muscle protein turnover have been suggested and the cellular hydration state was proposed to represent the link connecting muscle protein turnover to free glutamine concentrations [7,8]. Studies have indicated that glutamine supplementation is potentially effective in preventing side effects for patients receiving highdose chemotherapy and bone marrow transplantation [9].

Cobalt, nickel and copper are essential trace elements and are vital. Glutamine is synthesized by the liver. So there is every likely hood for their interaction in the liver. Hence these three metals are taken as representative systems to essential trace metals. Cobalt is essential for the production of the red blood cells and cobalamin $\left(\mathrm{B}_{12}\right.$ form) acts as the substrate for the enzymatic reaction that yields the active coenzyme derivatives of cyanocobalamin and aqua cobalamin [10]. Nickel is present in enzymes like urease [11] and any variation in its concentration leads to metabolic disorders. Copper is an essential trace nutrient to all higher plant and animal life. It is found primarily in the blood stream, as a co-factor in various enzymes and in copper-based pigments.

Most of the speciation studies are performed in aqueous media under conditions comparable to those existing in physiological systems. These are taken as models for the systems existing in biofluids and natural water. But biosystems are associated with low dielectric media of different magnitude and metabolic reactions are carried out under strictly compartmentalized conditions. Some studies were performed in aqua-organic mixtures to mimic these conditions but no attempt was made to account for the compartmentalization. For example, protonation and complexation equilibria of Gln in dioxane- [12], urea- [13, 14], ethylene glycol- [15],

*Corresponding author. E-mail: gollapallinr@yahoo.com 
acetonitrile- [16] and DMF-water [17] media have been studied in this laboratory. Hence, the speciation of the title systems has been studied in surfactant media, where micellisation leads to compartmentalization. Cetyltrimethylammonium bromide (CTAB) is a cationic surfactant which tends to denature proteins and profoundly influences the bulk properties of physiological systems. It can solubilise, concentrate and compartmentalize ions and molecules [18]. Hence, the influence of cationic micellar media (CTAB) on the chemical speciation of Gln has been investigated.

Literature survey indicates that the binary complexes of Gln were studied in aqueous medium. There were several instances where different species were reported for the same chemical system by different workers [19-26]. The probes utilized and the computational procedures adopted by these workers were sometimes the same and sometimes different. The discrepancies in the reported data are probably due to the difficulties associated with these types of studies. Further, different species proposed for the same metal-ligand system are many a time judged based on the best fit criteria. It is very difficult to say a final word about it, as it is unequivocally proved that different algorithms (or same algorithm with different weighting schemes) produce different species.

The $\mathrm{pH}$ metric technique (readability 0.001 ) is more sensitive and gives more precise values than the potentiometric and spectrophotometric methods used earlier. The earlier studies also used simple graphical and numerical methods which are prone to errors and thus determined stability constants are unreliable. In the present study the stability constants are calculated using the computer program MINIQUAD75, which exploits the advantage of constrained leastsquares method in the initial refinement and reliable convergence of Marquardt algorithm. Hence the best fit models proposed in the present study represent the system better than the earlier methods.

\section{EXPERIMENTAL}

\section{Materials}

$0.1 \mathrm{M}$ solution of L-glutamine (Merck, India) was prepared using triple-distilled water. Solutions of $\mathrm{Co}(\mathrm{II}), \mathrm{Ni}$ (II) and $\mathrm{Cu}$ (II) chlorides were prepared by maintaining $0.05 \mathrm{M}$ hydrochloric acid to suppress the hydrolysis of metal salts. CTAB (Merck, India) was used as received. 0.2 M hydrochloric acid (Qualigens, India) and 0.4 M sodium hydroxide (Qualigens, India) were prepared. $2 \mathrm{M}$ sodium chloride (Qualigens, India) solution was prepared to maintain the ionic strength in the titrand. The strengths of alkali and mineral acid were determined using the Gran plot method [27]. To assess the errors that might have crept into the determination of the concentrations, the data were subjected to analysis of variance of one way classification [28].

\section{Alkalimetric titrations}

The titrimetric data were obtained with Systronics $\mu \mathrm{pH}$ system (model 362) (readability 0.001). The $\mathrm{pH}$ meter was calibrated with a $0.05 \mathrm{M}$ potassium hydrogen phthalate solution in the acidic region and a $0.01 \mathrm{M}$ borax solution in the basic region. The glass electrode was equilibrated in a well-stirred CTAB-water mixture containing an inert electrolyte. The effects of variations in the asymmetry, liquid junction potential, activity coefficient, sodium ion error and dissolved carbon dioxide on the response of the glass electrode were accounted for in the form of correction factors [29].

The glass electrode was equilibrated in a well stirred CTAB-water mixture containing inert electrolyte for several days. At regular intervals strong acid was titrated against alkali to check the complete equilibration of the glass electrode. The calomel electrode was refilled with 
CTAB-water mixture of equivalent composition as that of the titrand. Free acid titrations were performed before the metal-ligand titrations to calculate the correction factor. In each of the titrations, the titrand consisted of a mineral acid of approximately $1 \mathrm{mmol}$ in a total volume of $50 \mathrm{~mL}$. Titrations with different ratios (1:2.5, 1:3.5 and 1:5) of metal-to-ligand were performed with $0.4 \mathrm{M}$ sodium hydroxide (Table 1 ).

Table 1. Total initial concentrations of ingredients (in mmol) in titrands (temperature $=303 \mathrm{~K}$, ionic strength $=0.16 \mathrm{M})$.

\begin{tabular}{|l|l|l|l|l|l|}
\hline CTAB \%w/v & Gln & Co(II) & Ni(II) & Cu(II) & M:L \\
\hline 0.0 & 0.5009 & 0.1998 & 0.1998 & 0.1996 & $1: 2.5$ \\
& 0.7012 & 0.1998 & 0.1998 & 0.1996 & $1: 3.5$ \\
& 1.0018 & 0.1988 & 0.1988 & 0.1996 & $1: 5.0$ \\
\hline 0.5 & 0.5008 & 0.1998 & 0.1998 & 0.1996 & $1: 2.5$ \\
& 0.7012 & 0.1998 & 0.1998 & 0.1996 & 1.3 .5 \\
& 1.0017 & 0.1998 & 0.1998 & 0.1996 & $1: 5.0$ \\
\hline 1.0 & 0.5008 & 0.1998 & 0.1998 & 0.1996 & $1: 2.5$ \\
& 0.7012 & 0.1998 & 0.1998 & 0.1996 & $1: 3.5$ \\
& 1.0017 & 0.1998 & 0.1998 & 0.1996 & $1: 5.0$ \\
\hline 1.5 & 0.5009 & 0.1998 & 0.1998 & 0.1996 & $1: 2.5$ \\
& 0.7012 & 0.1998 & 0.1998 & 0.1996 & $1: 3.5$ \\
& 1.0018 & 0.1998 & 0.1998 & 0.1996 & $1: 5.0$ \\
\hline 2.0 & 0.5008 & 0.1998 & 0.1998 & 0.1996 & $1: 2.5$ \\
& 0.7012 & 0.1998 & 0.1998 & 0.1996 & $1: 3.5$ \\
& 1.0017 & 0.1998 & 0.1998 & 0.1996 & $1: 5.0$ \\
\hline 2.5 & 0.5009 & 0.1998 & 0.1998 & 0.1996 & $1: 2.5$ \\
& 0.7012 & 0.1998 & 0.1998 & 0.1996 & $1: 3.5$ \\
& 1.0017 & 0.1998 & 0.1998 & 0.1996 & $1: 5.0$ \\
\hline
\end{tabular}

\section{Modeling strategy}

The protonation constants and the binary stability constants were calculated with the computer program MINIQUAD75 [30]. During the refinement of binary systems, the correction factor and the protonation constants were fixed.

\section{RESULTS AND DISCUSSION}

\section{Secondary formation functions}

Secondary formation functions like average number of moles of protons bound per mole of ligand, $\overline{\mathrm{n}} \mathrm{H}$, and number of moles of alkali consumed per mole of ligand (a) are useful to detect the number of equilibria. Overlapping plots of $\overline{\mathrm{n}} \mathrm{H}$ versus $\mathrm{pH}$ for different concentrations of glutamine (Figure 1) rule out the polymerization of the ligand molecules. The $\mathrm{pH}$ values at half integral values of $\overline{\mathrm{n}} \mathrm{H}$ correspond to the protonation constants of the ligand. Two half integrals (1.5 and 0.5) of glutamine (Figure 1) emphasize the presence of two protonation-deprotonation equilibria in the $\mathrm{pH}$ range of present study. The number of plateaus in the formation curves corresponds to the number of these equilibria. Glutamine has two ionizable (carboxylic and amino) protons and its cationic form $\left(\mathrm{LH}_{2}^{+}\right)$possesses two protonation constants with two potential co-ordination centers.

The plots of a versus $\mathrm{pH}$ are given in Figure 2. The negative values of a correspond to the number of moles of free acid present in the titrand and the number of associable protons. The positive values of a indicate the number of dissociable protons in the ligand molecules. The 
maximum value of $\mathbf{a}$ in Figure 2 is one, which clearly infers that Gln has one dissociable (carboxyl) proton.

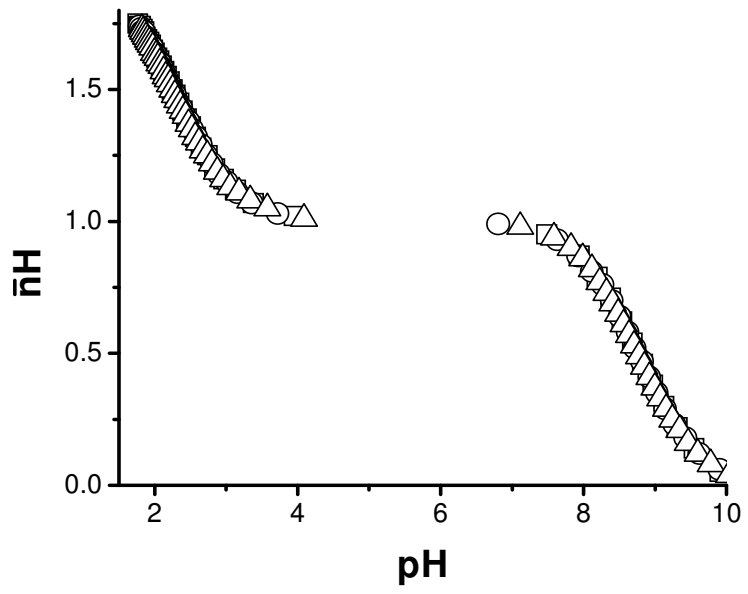

Figure 1. Formation curves in $2.0 \%$ w/v CTAB-water mixture; amount of Gln ( $\square)$ 0.5, (०) 0.7 and $(\Delta) 1.0 \mathrm{mmol}$.

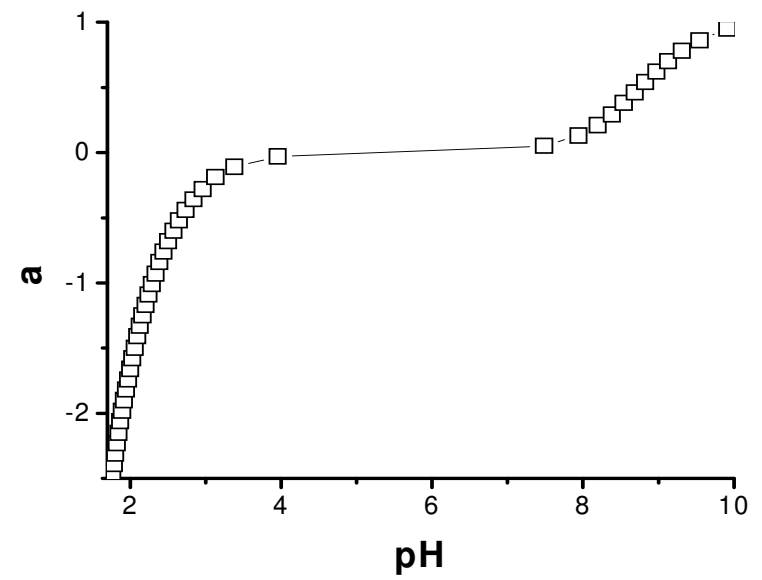

Figure 2. Variation of a with $\mathrm{pH}$ in $2.0 \% \mathrm{w} / \mathrm{v} \mathrm{CTAB}$-water mixture.

The best fit models containing the type of species and $\log$ values of overall formation constants $(\log \beta)$ along with some of the important statistical parameters of the present study are given in Tables 2 and 3. A very low standard deviation (SD) in $\log \beta$ values, $U_{\text {corr }}$ (sum of the squares of deviations in the concentrations of ingredients at all experimental points corrected for degrees of freedom) indicate that the experimental data can be represented by the model. Protonation constants obtained agreed with those of earlier studies made in acetonitrile-water media [16]. Small values of mean, standard deviation and mean deviation for the systems corroborate that the residuals are around a zero mean with little dispersion. 
Table 2. Protonation constants of Gln in CTAB-water mixtures (Temperature $=303 \mathrm{~K}$, Ionic strength $=$ $0.16 \mathrm{M}, \mathrm{pH}$ range $=2.0-9.3$ ).

\begin{tabular}{|l|l|l|l|l|c|c|c|c|}
\hline$\% \mathrm{w} / \mathrm{v} \mathrm{CTAB}$ & $\log \beta_{1}(\mathrm{SD})$ & $\log \beta_{2}(\mathrm{SD})$ & $\mathrm{NP}$ & $\mathrm{U}_{\text {corr }}$ & Skewness & Kurtosis & $\chi^{2}$ & $\mathrm{R}$ \\
\hline 0.0 & $8.96(4)$ & $11.19(6)$ & 110 & 2.67 & 0.11 & 6.74 & 23.3 & 0.006 \\
\hline 0.5 & $9.02(4)$ & $11.09(6)$ & 151 & 3.45 & -0.37 & 2.78 & 8.94 & 0.006 \\
\hline 1.0 & $8.72(5)$ & $10.81(8)$ & 112 & 4.61 & -0.07 & 4.32 & 10.8 & 0.008 \\
\hline 1.5 & $8.68(4)$ & $10.72(6)$ & 111 & 2.74 & 0.37 & 3.12 & 6.47 & 0.006 \\
\hline 2.0 & $8.76(3)$ & $11.00(5)$ & 117 & 2.28 & 0.81 & 3.85 & 10.3 & 0.005 \\
\hline 2.5 & $8.74(7)$ & $10.87(11)$ & 114 & 8.88 & 0.72 & 4.65 & 32.4 & 0.011 \\
\hline
\end{tabular}

$\mathrm{U}_{\text {corr }}=\mathrm{U} /(\mathrm{NP}-\mathrm{m}) \times 10^{8} ; \mathrm{NP}=$ number of points; $\mathrm{m}=$ number of protonation constants; $\mathrm{SD}=$ standard deviation.

Table 3. Parameters of best fit chemical models of glutamine complexes in CTAB-water mixtures (temperature $=303 \mathrm{~K}$, ionic strength $=0.16 \mathrm{M}$ ).

\begin{tabular}{|c|c|c|c|c|c|c|c|c|c|c|}
\hline \multirow{2}{*}{$\begin{array}{l}\text { CTAB } \\
\% \text { w/v }\end{array}$} & \multicolumn{4}{|c|}{$\log \beta_{\mathrm{mlh}}(\mathrm{SD})$} & \multirow{2}{*}{ NP } & \multirow{2}{*}{$\mathrm{U}_{\text {corr }} \times 10^{8}$} & \multirow{2}{*}{ Skewness } & \multirow{2}{*}{$\chi^{2}$} & \multirow{2}{*}{ R-Factor } & \multirow{2}{*}{ Kurtosis } \\
\hline & 110 & 111 & 120 & 121 & & & & & & \\
\hline \multicolumn{11}{|c|}{$\mathrm{Co}(\mathrm{II})(\mathrm{pH}$ range $1.5-8.0)$} \\
\hline 0.0 & $4.05(24)$ & $10.72(3)$ & $7.55(6)$ & $15.21(20)$ & 133 & 2.61 & -0.49 & 146.46 & 0.005 & 6.18 \\
\hline 0.5 & $3.92(13)$ & $10.87(1)$ & $7.52(3)$ & $15.22(8)$ & 133 & 0.62 & 0.17 & 110.97 & 0.002 & 5.68 \\
\hline 1.0 & $4.16(41)$ & $11.00(5)$ & $7.77(10)$ & $15.17(43)$ & 134 & 9.36 & -0.28 & 114.86 & 0.009 & 6.19 \\
\hline 1.5 & $4.95(48)$ & $11.85(9)$ & $8.63(14)$ & $15.88(65)$ & 136 & 19.13 & 0.33 & 106.98 & 0.013 & 5.71 \\
\hline 2.0 & $4.46(19)$ & $11.33(4)$ & $8.25(5)$ & 15.54(19) & 94 & 2.27 & 0.17 & 48.11 & 0.005 & 3.03 \\
\hline 2.5 & $4.55(59)$ & $11.41(5)$ & $8.80(10)$ & $15.99(31)$ & 140 & 11.39 & -0.06 & 16.38 & 0.010 & 3.04 \\
\hline \multicolumn{11}{|c|}{$\mathrm{Ni}(\mathrm{II})$ (pH range 1.5-8.0) } \\
\hline 0.0 & $4.99(20)$ & $10.63(3)$ & $9.77(4)$ & $16.46(9)$ & 141 & 1.55 & 0.20 & 124.91 & 0.003 & 10.09 \\
\hline 0.5 & $5.08(10)$ & $10.69(4)$ & $9.26(4)$ & $15.78(21)$ & 99 & 1.68 & -0.08 & 68.98 & 0.004 & 4.18 \\
\hline 1.0 & $5.22(25)$ & $10.69(8)$ & $9.58(9)$ & $15.87(60)$ & 142 & 11.27 & -0.19 & 199.62 & 0.010 & 6.71 \\
\hline 1.5 & $5.07(16)$ & $10.38(6)$ & $9.59(5)$ & $15.97(23)$ & 142 & 3.13 & 0.59 & 70.98 & 0.005 & 4.03 \\
\hline 2.0 & $5.03(26)$ & $10.42(7)$ & $9.72(7)$ & $16.13(24)$ & 143 & 5.45 & 0.66 & 67.09 & 0.007 & 4.56 \\
\hline 2.5 & $5.32(45)$ & $11.28(4)$ & $10.50(7)$ & $16.92(17)$ & 145 & 6.60 & 0.70 & 92.06 & 0.008 & 4.54 \\
\hline \multicolumn{11}{|c|}{$\mathrm{Cu}(\mathrm{II})(\mathrm{pH}$ range $1.5-6.0)$} \\
\hline 0.0 & $8.78(45)$ & $12.15(45)$ & $15.53(43)$ & $19.65(70)$ & 95 & \begin{tabular}{|l|}
38.98 \\
\end{tabular} & 2.92 & 740.54 & 0.023 & 119.68 \\
\hline 0.5 & $7.84(9)$ & $11.05(6)$ & $14.53(5)$ & $18.68(15)$ & 94 & 2.71 & -0.45 & 11.16 & 0.006 & 3.58 \\
\hline 1.0 & $7.38(10)$ & $10.48(7)$ & $13.90(5)$ & $17.86(17)$ & 92 & 2.92 & -0.35 & 50.96 & 0.006 & 5.01 \\
\hline 1.5 & $7.31(17)$ & $10.51(9)$ & $14.11(6)$ & $18.16(12)$ & 92 & 4.53 & -0.42 & 46.14 & 0.008 & 5.95 \\
\hline 2.0 & $7.34(15)$ & $10.69(5)$ & $14.24(4)$ & $18.56(6)$ & 98 & 2.50 & -0.23 & 68.88 & 0.005 & 5.39 \\
\hline 2.5 & $7.80(7)$ & $10.92(4)$ & $14.78(3)$ & $18.57(7)$ & 97 & 1.08 & 1.14 & 27.98 & 0.004 & 8.82 \\
\hline
\end{tabular}

\section{Residual analysis}

In data analysis with least squares methods, the residuals (the differences between the experimental data and the data simulated based on the model parameters) are assumed to follow Gaussian distribution. Further, a model is considered adequate only if the residuals do not show any trend. Respecting the hypothesis of the least squares analysis, the residuals are tested for normal distribution, using $\chi^{2}$, skewness, kurtosis and R-factor. These statistical parameters [31] show that the best fit models portray the acido-basic and metal ligand equilibria of Gln in CTAB-water mixtures, as discussed below.

Alkalimetric titration data are simulated using the model parameters given in Table 2. These data are compared with the experimental alkalimetric titration data, to verify the sufficiency of the models. The overlap of the typical experimental and simulated titrations data given in Figure 3 indicates that the proposed models represent the experimental data. 


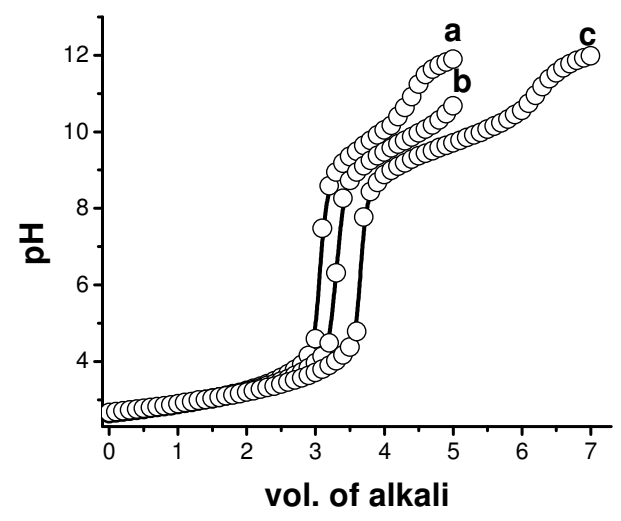

Figure 3. Simulated (o) and experimental (solid line) alkalimetric titration curves in $2.0 \% \mathrm{w} / \mathrm{v}$ CTAB-water mixture; Gln (a) 0.5, (b) 0.7 and (c) 1.0 mmol.

\section{Effect of systematic errors in best fit model}

In order to rely upon the best chemical model for critical evaluation and application under varied experimental conditions with different accuracies of data acquisition, an investigation was made by introducing pessimistic errors in the concentrations of alkali, mineral acid, ligand and metal (Table 4). The order of the compounds that influence the magnitudes of the stability constants due to incorporation of errors is alkali $>$ acid $>$ ligand $>$ metal. Some species, such as ML, MLH, $\mathrm{ML}_{2}$ and $\mathrm{ML}_{2} \mathrm{H}$ were even rejected when errors were introduced in the concentrations of the components. This shows that any deviation from the experimental concentrations of the components increases the standard deviation in the $\log \beta$ values and results ultimately in the rejection of the species. This study infers that the experimental concentrations are appropriate and the proposed models are adequate for the experimental data.

Table 4. Effect of errors in influential parameters on stability constants of $\mathrm{Co}$ (II) with glutamine in $2.0 \%$ (w/v) CTAB-water mixture.

\begin{tabular}{|l|l|l|l|l|l|}
\hline Ingredient & \% Error & \multicolumn{4}{|c|}{$\log \beta_{\operatorname{mlh}}(\mathrm{SD})$} \\
\cline { 3 - 6 } & & 110 & 111 & 120 & 121 \\
\hline & 0 & $4.46(19)$ & $11.33(4)$ & $8.25(5)$ & $15.54(19)$ \\
\hline Alkali & -5 & $3.57(11)$ & $9.62(64)$ & $6.58(10)$ & Rejected \\
& -2 & $4.20(15)$ & $10.93(4)$ & $7.54(6)$ & $14.56(62)$ \\
& +2 & $5.04(35)$ & $11.76(9)$ & $9.05(10)$ & $16.20(31)$ \\
& +5 & Rejected & Rejected & Rejected & Rejected \\
\hline Acid & -5 & Rejected & Rejected & Rejected & Rejected \\
& -2 & $5.45(34)$ & $12.15(15)$ & $9.35(16)$ & $16.52(36)$ \\
& +2 & $4.15(13)$ & $10.65(5)$ & $7.46(5)$ & $13.80(251)$ \\
& +5 & $3.57(12)$ & Rejected & $6.73(9)$ & Rejected \\
\hline Ligand & -5 & $4.31(18)$ & $10.98(4)$ & $8.09(5)$ & $15.26(24)$ \\
& -2 & $4.39(19)$ & $11.20(4)$ & $8.18(5)$ & $15.42(21)$ \\
& +2 & $4.55(20)$ & $11.48(4)$ & $8.34(5)$ & $15.66(17)$ \\
& +5 & $4.72(23)$ & $11.72(5)$ & $8.50(6)$ & $15.86(19)$ \\
\hline Metal & -5 & $4.53(22)$ & $11.39(4)$ & $8.39(5)$ & $15.58(22)$ \\
& -2 & $4.48(21)$ & $11.36(4)$ & $8.31(5)$ & $15.56(20)$ \\
& +2 & $4.45(19)$ & $11.31(4)$ & $8.20(5)$ & $15.52(18)$ \\
& +5 & $4.42(17)$ & $11.28(3)$ & $8.12(5)$ & $15.48(18)$ \\
\hline
\end{tabular}

Bull. Chem. Soc. Ethiop. 2012, 26(3) 


\section{Effect of surfactant}

Many workers were of the opinion that both electrostatic and non-electrostatic effects should be considered even in the case of simple acido-basic equilibria; one dominates the other, depending upon the nature of solute and solvent [32-34]. Born's classical treatment [35] holds good in accounting for the electrostatic contribution to the free energy change. The number of micelles increases with the concentration of surfactant and oppositely charged ions are concentrated in the Stern layer. Figure 4 shows the linear variation of the step-wise protonation constants of glutamine with the mole fraction of $\mathrm{CTAB}$, may be because of the electrostatic interaction.

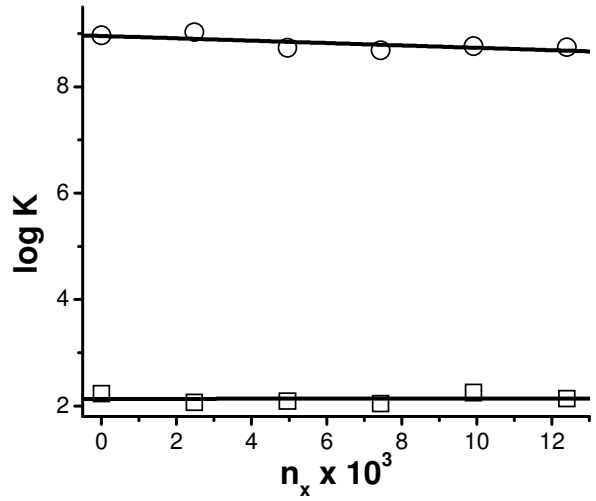

Figure 4. Variation of step-wise protonation constant $(\log K)$ of Gln with mole fraction of CTAB-water mixture ( $\square) \log \mathrm{K}_{1}(\circ) \log \mathrm{K}_{2}$.

Micelles alter the reaction rates and shift equilibria primarily by concentrating reactants within the small volume of micellar pseudo phase. The extent of change is a product of the micellar effect on the reaction within the micellar pseudo phase and the distribution of reactants between the two phases. The effect of micelles on overall reaction rates and equilibria depends upon the incorporation of solutes into the micellar pseudo phase.

The effect of surfactant on complex equilibria and apparent shift in the magnitude of stability constants in micellar media can be attributed [36] to the creation of a concentration gradient of proton between the interface and the bulk solution. The number of micelles increases with the concentration of surfactant, and oppositely charged ions are concentrated in the Stern layer [37]. CTAB has a positive polar head and hence, negatively charged ligand ions are concentrated in the Stern layer where as hydrogen ions are pushed into the bulk solvent. The deprotonated carboxylate ions are stabilized compared to the protonated forms by the cationic micelles due to the formation of ion pairs. The stability constants $(\log \beta)$ varied linearly with mole fraction of CTAB due to the polarity of the medium, charge on the micellar surface and due to the electrostatic forces/hydrophobic interactions operating between the complex species and micellar surface. The species are stabilized in the micellar medium with opposite charges due to electrostatic interactions. The linear or almost linear variations of stability constants (log $\beta$ ) with the mole fraction of CTAB (Figure 5) indicate the dominance of electrostatic forces over non-electrostatic forces $[38,39]$. The non-linearity may be due to the relative contributions of the structure-forming nature and complexing ability of CTAB. One of the reasons for such behavior is accumulation of metal ion and ligand on the surface of the micelles with increased concentration of surfactant. 
(A)

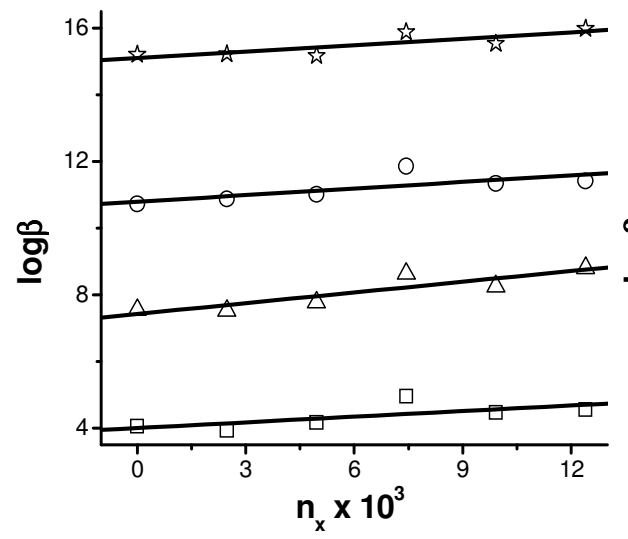

(B)

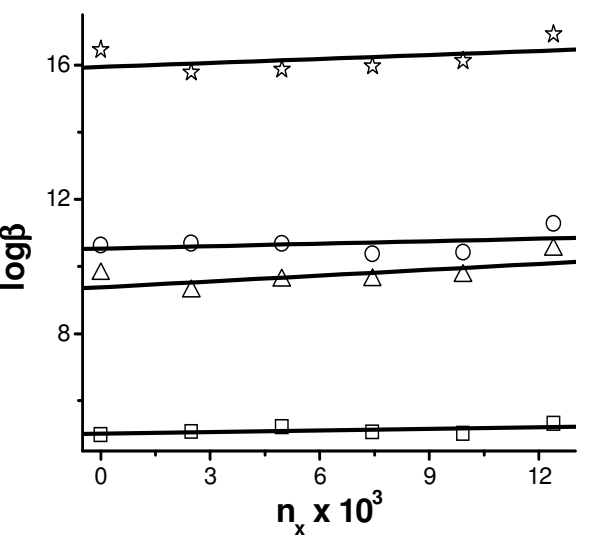

(C)

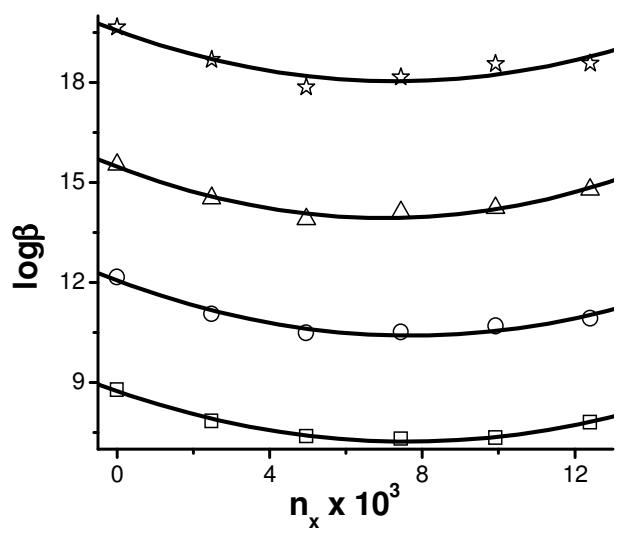

Figure 5. Variation of overall stability constant values of metal-glutamine complexes $(\log \beta)$ with mole fraction of CTAB-water mixtures. (A) $\mathrm{Co}$ (II), (B) $\mathrm{Ni}$ (II) and (C) $\mathrm{Cu}(\mathrm{II})$; (口) $\log \beta_{110}$, (O) $\log \beta_{111}(\Delta) \log \beta_{120}$, (汭) $\log \beta_{121}$.

\section{Distribution diagrams}

The existence of $\mathrm{LH}_{2}^{+}, \mathrm{LH}$ and $\mathrm{L}^{-}$in different $\mathrm{pH}$ ranges is exhibited by the distribution plots (Figure 6) of various forms of glutamine. As alkali is added to the titrand containing the ligand, the protonated forms of the ligand lose protons, carboxyl followed by amino, successively [16].

The species refined and formed by Gln with $\mathrm{Co}(\mathrm{II}), \mathrm{Ni}(\mathrm{II})$ and $\mathrm{Cu}(\mathrm{II})$ in the present study are $\mathrm{MLH}, \mathrm{ML}, \mathrm{ML}_{2} \mathrm{H}$ and $\mathrm{ML}_{2}$. The $\mathrm{ML}_{2}$ species is the predominant species (Figure 7) among all the binary complexes. Low concentration of free metal ion (FM) indicates the strong complexing nature of glutamine. The formation of various binary complex species is shown in the following equilibria: 


$$
\begin{array}{lll}
\mathrm{M}(\mathrm{II})+\mathrm{LH}_{2} & \rightleftharpoons & \mathrm{MLH}+\mathrm{H}^{+} \\
\mathrm{MLH} & \rightleftharpoons & \mathrm{ML}+\mathrm{H}^{+} \\
\mathrm{M}(\mathrm{II})+\mathrm{LH}_{2} & \mathrm{ML}+2 \mathrm{H}^{+} \\
\mathrm{M}+2 \mathrm{LH}_{2} & \rightleftharpoons & \mathrm{ML}_{2} \mathrm{H}+3 \mathrm{H}^{+} \\
\mathrm{MLH}+\mathrm{LH} & \rightleftharpoons & \mathrm{ML}_{2} \mathrm{H}+\mathrm{H}^{+} \\
\mathrm{ML}_{2} \mathrm{H} & \rightleftharpoons & \mathrm{ML}_{2}+\mathrm{H}^{+} \\
\mathrm{M}(\mathrm{II})+2 \mathrm{LH} & \mathrm{ML}_{2}+2 \mathrm{H}^{+}
\end{array}
$$

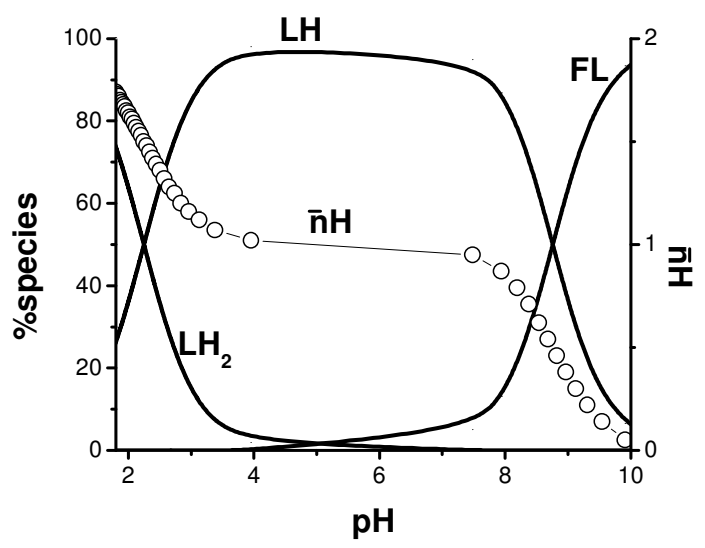

Figure 6. Formation function $(\circ)$ and species distribution diagram of glutamine in $2.0 \% \mathrm{w} / \mathrm{v}$ CTAB-water mixture.

Formation of MLH with decreasing concentration of FM is explained by Equilibrium 1 (Figure 7). Simultaneous increase in the concentrations of $\mathrm{ML}$ and $\mathrm{ML}_{2} \mathrm{H}$ with decreasing concentrations of MLH and $\mathrm{LH}_{2}$ infers the simultaneous existence of Equilibria 2-4. The formation of $\mathrm{ML}_{2} \mathrm{H}$ through Equilibria 4 and 5 is proved by the decreasing concentrations of MLH and LH. Formation of $\mathrm{ML}_{2}$ suggests its formation through Equilibria 6 and 7.

Structures of complexes

$\mathrm{Co}$ (II), $\mathrm{Ni}$ (II) and $\mathrm{Cu}$ (II) form octahedral complexes. Hence the hypothetical structures for the above complexes are proposed in Figure 8. These structures support the existence of protonated and deprotonated complexes shown in Equilibria 1-7. 


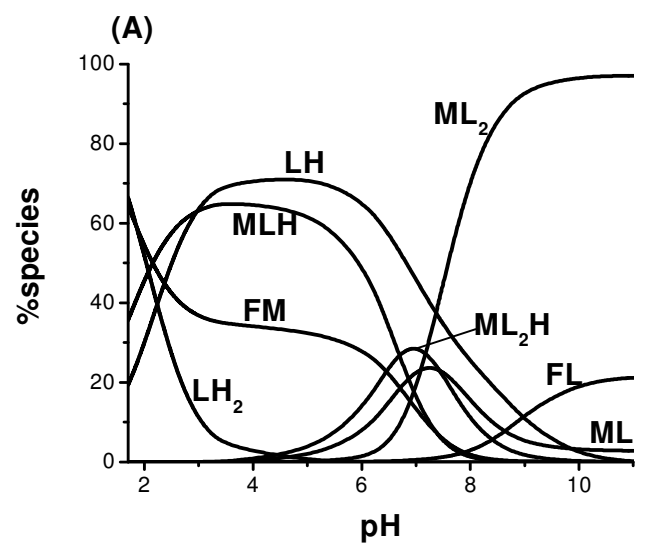

(B)
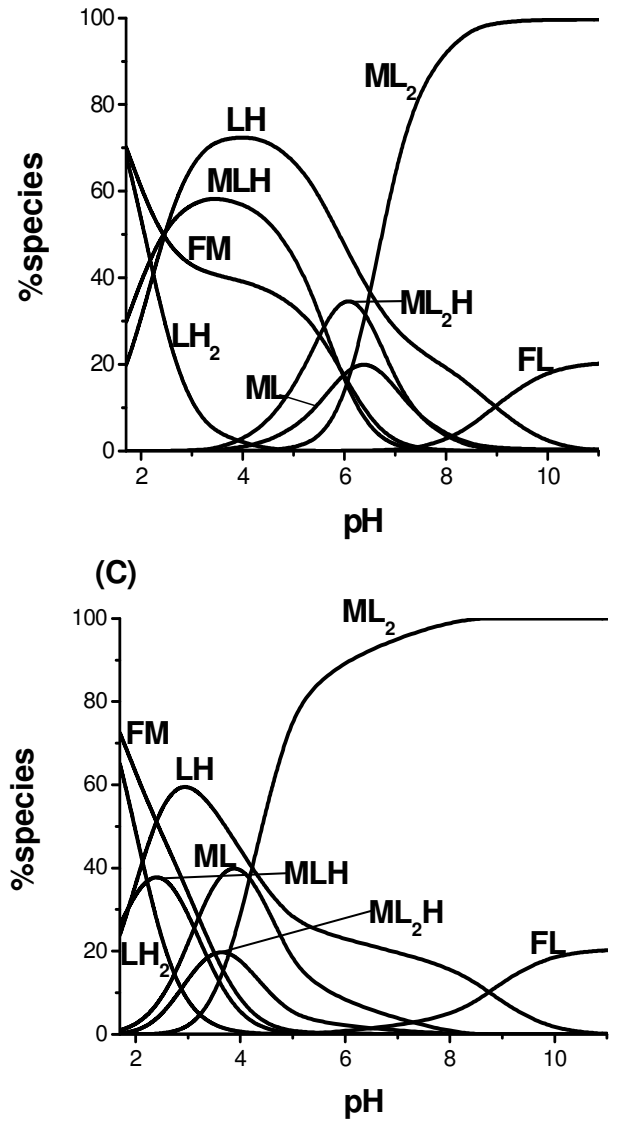

Figure 7. Distribution diagrams of L-glutamine complexes in $2.5 \% \mathrm{w} / \mathrm{v}$ CTAB-water mixture; (A) $\mathrm{Co}$ (II), (B) $\mathrm{Ni}$ (II) and (C) $\mathrm{Cu}(\mathrm{II})$. 


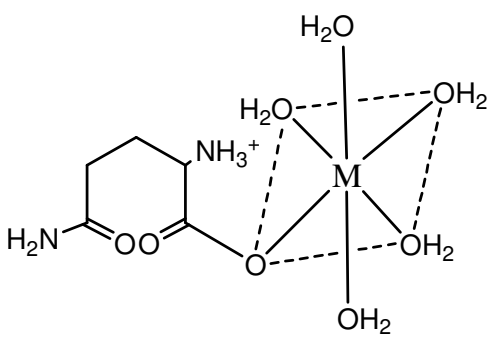

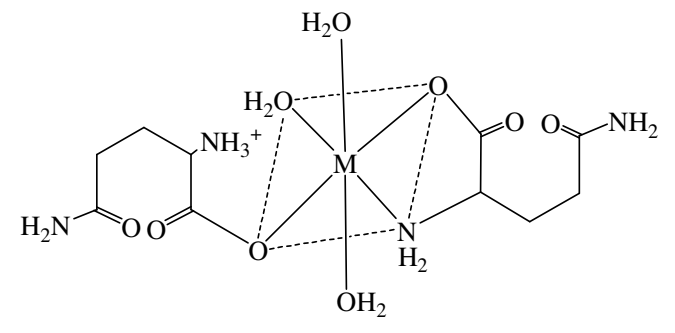

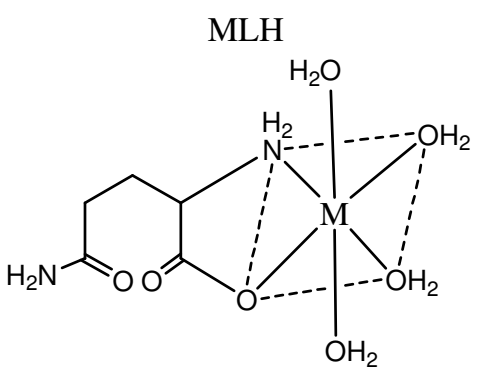

ML

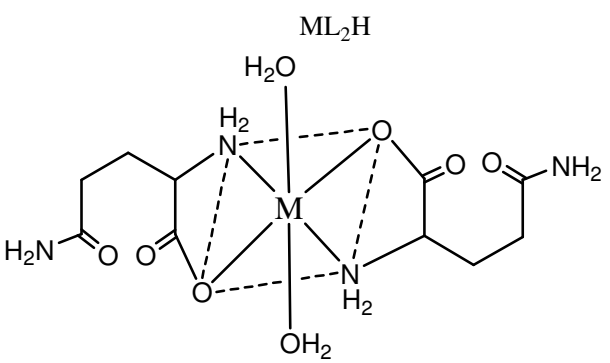

$\mathrm{ML}_{2}$

Figure 8. Hypothetic structures of L-glutamine complexes with the metal, $\mathrm{M}=\mathrm{Co}(\mathrm{II}), \mathrm{Ni}(\mathrm{II})$, $\mathrm{Cu}(\mathrm{II})$.

\section{CONCLUSIONS}

L-Glutamine forms both protonated and unprotonated complexes in the $\mathrm{pH}$ range 2.0-9.3. Secondary formation functions are used in detecting the number of equilibria and in guessing the approximate constants. As glutamine is successively protonated, the charge of the species is decreased and low dielectric medium favours the protonation of ligand due to dominant electrostatic interactions. The predominant binary complex species detected are MLH, ML, $\mathrm{ML}_{2} \mathrm{H}$ and $\mathrm{ML}_{2}$. These models are validated by statistical treatment of the data. The linear or almost linear variation of $\log \beta$ values with the mole fraction of the medium indicates the dominance of electrostatic forces over non-electrostatic forces. The linear increasing trend with $\mathrm{CTAB}$ concentration supports the predominance of the structure forming nature of cation surfactant over its complexing ability. The order of ingredients influencing the magnitudes of the stability constants due to the incorporation of errors is alkali $>$ acid $>$ ligand $>$ metal.

\section{REFERENCES}

1. Bergström, J.; Fürst, P.; Noree, L.O.; Vinnars, E. J. Appl. Physiol. 1974, 36, 693.

2. Hankard, R.G.; Darmaun, D.; Sager, B.K.; D’Amore, D.; Parsons, W.R.; Haymond, M.W. Am. J. Physiol. 1995, 269, E663.

3. Herskowitz, K.; Souba, W.W. Nutrition 1990, 6, 199.

4. Souba, W.W. Annu. Rev. Nutr. 1991, 11, 285.

5. Calder, P.C. Clin. Nutr. 1994, 13, 2. 
6. Newsholme, E.A.; Calder, P.C. Nutrition 1997, 13, 728.

7. Jepson, M.M.; Bates, P.C.; Broadbent, P.; Pell, J.M.; Millward, D.J. Am. J. Physiol. 1988, 255, E166.

8. Häussinger, D.; Roth, E.; Lang, F.; Gerok, W. Lancet 1993, 341, 1330.

9. Ziegler, T.R. Br. J. Nutr. 2002, 87(Suppl 1), S9.

10. Underwood, E.J. Trace Elements in Human and Animal Nutrition, 4th ed., Academic Press: New York; 1977; $\mathrm{p} 1$.

11. Poellot, R.A.; Shuler, T.R.; Uthus, E.O.; Nielsen, F.H. Proc. Natl. Acad. Sci. USA 1990, 44, 80 .

12. Koseoglu, F.; Kilic, E.; Dogan, A. Anal. Biochem. 2000, 277, 243.

13. Rao, G.N.; Murthy, V.L.S.N. J. Indian Chem. Soc. 2004, 81, 424.

14. Rao, G.N.; Ramakrishna, A. Proc. Natl. Acad. Sci. India 2005, 75A, 245.

15. Rao, G.N.; Ronald, S.B. J. Indian Chem. Soc. 2002, 79, 796.

16. Rao, G.N.; Ronald, S.B. J. Indian Chem. Soc. 2002, 79, 416.

17. Rao, G.N.; Ramakrishna, A. Proc. Nat. Acad. Sci. India 2007, 77A, 287.

18. Pelizetti, E.; Pramaro, E. Anal. Chim. Acta 1983, 169, 1.

19. Malhotra, S.; Singh, R.K.P.; Yadav, K.L. Trans SAEST1993, 28, 42.

20. Martell, A.E. (Ed.) Critical Stability Constants, Vol. 1, Plenum Press: New York; 1974; p 41.

21. Kruck, T.P.A.; Sarkar, B. Can. J. Chem. 1973, 51, 3562.

22. Janarthanam, M.; Sivasankar, B.; Rangaraj, K. Indian J. Chem. 1995, 34A, 201.

23. Yamanchi, O.; Takaba, T.; Sakurai, T. Bull. Chem. Soc. Jpn. 1980, 53, 160.

24. Rao, G.N.; Ronald, S.B. Proc. Nat. Acad. Sci.India 2004, 74A, 301.

25. Murthy, V.L.S.N. Ph.D. Thesis, Andhra University, Visakhapatnam, India, 2002.

26. Srikanth, B.; Rao, P.S.; Rao, V.S.; Sastry, C.K.; Rao, G.N. J. Serb. Chem. Soc. 2009, 74, 745.

27. Gran, G. Anal. Chim. Acta 1988, 206, 111.

28. Rao, R.S.; Rao, G.N. Computer Applications in Chemistry, Himalaya Publishing House: Mumbai; 2005; p 302.

29. Latha, M.P.; Rao, V.M.; Rao, T.S.; Rao, G.N.; Bull. Chem. Soc. Ethiop. 2007, 21, 363.

30. Gans, P.; Sabatini, A.; Vacca, A. Inorg. Chim. Acta 1976, 18, 237.

31. Rao, R.S.; Rao, G.N. Computer Applications in Chemistry, Himalaya Publishing House: Mumbai; 2005; p 277.

32. Schneider, H. Top. Curr. Chem. 1976, 68, 103.

33. Abraham, M.H.; Liszi, J. J. Inorg. Nucl. Chem. 1981, 43, 143.

34. Feakins, D.; Neille, R.D.O.; Woghonie, W.E. J. Chem. Soc. Faraday Trans. 1983, 2289.

35. Born, M. Z. Phys. 1920, 1, 45.

36. Hartly, G.S; Roe, J.W. Trans. Faraday Soc. 1940, 36, 101.

37. Bunton, C.A.; Cerichelli, G.; Ihara, Y.; Supulveda, L. J. Am. Chem. Soc. 1979, 101, 2429.

38. Singh, A.K.; Manjula, D. J. Indian Chem. Soc. 2001, 71, 635.

39. Cordes, E.H. Pure Appl. Chem. 1978, 50, 617. 